\title{
TITLE:
}

\section{Off-Pump Bilateral Cadaveric Lung Transplantation Is Associated With Profound Intraoperative Hypothermia}

\section{$\operatorname{AUTHOR(S):~}$}

Dong, Li; Mizota, Toshiyuki; Tanaka, Tomoharu; Chen-Yoshikawa, Toyofumi F.; Date, Hiroshi; Fukuda, Kazuhiko

\section{CITATION:}

Dong, Li ... [et al]. Off-Pump Bilateral Cadaveric Lung Transplantation Is Associated With Profound Intraoperative Hypothermia. Journal of Cardiothoracic and Vascular Anesthesia 2016, 30(4): 924-929

\section{ISSUE DATE:}

2016-08

URL:

http://hdl.handle.net/2433/226011

\section{RIGHT:}

(c) 2016. This manuscript version is made available under the CC-BY-NC-ND 4 olicense

http://creativecommons.org/licenses/by-nc-nd/4.0/; The full-text file will be made open to the public on 01 August 2017 in accordance with publisher's 'Terms and Conditions for Self-Archiving'; This is not the published version. Please cite only the published version.; この論文は出版社版でありません。引用の際には出版社版をご確認ご利用ください。 
Off-Pump Bilateral Cadaveric Lung Transplantation is Associated with Profound Intraoperative Hypothermia

Li Dong, MD, ${ }^{*}$ Toshiyuki Mizota, MD, ${ }^{*}$ Tomoharu Tanaka, MD, PhD, ${ }^{*}$ Toyofumi $\mathrm{F}$ Chen-Yoshikawa, MD, PhD,$\uparrow$ Hiroshi Date, $\mathrm{MD}, \mathrm{PhD}, \uparrow$ Kazuhiko Fukuda, MD, $\mathrm{PhD} *$

Departments of *Anesthesia and †Thoracic Surgery, Kyoto University Hospital, Kyoto, Japan

Corresponding author: Toshiyuki Mizota, MD

Mailing address: Department of Anesthesia, Kyoto University Hospital, 54 ShogoinKawahara-Cho, Sakyo-Ku, Kyoto 606-8507, Japan

Tel: +81-75-751-3433, Fax: +81-75-752-3259

E-mail: mizota@,kuhp.kyoto-u.ac.jp

Acknowledgments

The authors would like to thank Enago (www.enago.jp) for the English language review. 


\section{Abstract}

Objective. Changes in body temperature (BT) during lung transplantation have never been reported. The authors investigated the time-dependent changes in BT during lung transplantation and compared them between off-pump lung transplantation and lung transplantation using extracorporeal membrane oxygenation (ECMO).

Design. A retrospective observational study.

Setting. University hospital.

Participants. Patients who underwent cadaveric lung transplantation [15 bilateral lung transplantation (BLT) and 31 single lung transplantation (SLT)].

Interventions. None.

Measurements and Main Results. All patients received multimodal therapy to prevent intraoperative hypothermia, including increased environmental temperature, intravenous fluid warming, and the use of forced-air and circulating water warmers. Data of BT during the operation were collected, and the time course and the extent of BT decrease during the operation were analyzed. $66.7 \%$ of BLT patients and $35.5 \%$ of SLT patients required ECMO support during the operation; patient characteristics were comparable between off-pump and ECMO supported lung transplantation. In patients undergoing off-pump BLT, BT decreased continuously to $32.9^{\circ} \mathrm{C}$ when reperfusion was completed, and gradually recovered thereafter. The decrease in BT was significantly larger during off-pump BLT compared with ECMO-supported BLT $\left(3.5^{\circ} \mathrm{C} \pm 0.5^{\circ} \mathrm{C}\right.$ compared with $0.6^{\circ} \mathrm{C} \pm 0.5^{\circ} \mathrm{C}, \mathrm{P}=0.002$ ) and was $\geq 3^{\circ} \mathrm{C}$ in all patients. Patients undergoing off-pump SLT had a similar time trend for their BTs (continuous decrease until reperfusion and subsequent recovery), but the extent of BT decrease was much smaller than that in offpump BLT patients $\left(1.0^{\circ} \mathrm{C} \pm 0.5^{\circ} \mathrm{C}\right)$. 
Conclusion. Patients undergoing off-pump BLT were at high risk of profound intraoperative hypothermia despite multimodal preventive therapy.

Key words: lung transplantation, hypothermia, arrhythmia, extracorporeal membrane oxygenation 


\section{Introduction}

Perioperative hypothermia may contribute to serious adverse outcomes, including cardiac events [1], wound infection [2], coagulopathy and increased allogeneic transfusion requirements [3], and prolonged recovery [4]. Thus, it is now standard care to warm patients during surgery.

Lung transplantation has been performed successfully in a significant number of patients and has become an established therapeutic option for patients with end-stage lung disease $[5,6]$. Single lung transplantation (SLT) can be performed without cardiopulmonary bypass (CPB) or extracorporeal membrane oxygenation (ECMO) using one lung ventilation. In bilateral lung transplantation (BLT), bilateral sequential lung transplant technique is generally performed through a bilateral transverse thoracosternotomy (clamshell incision) [7], and therefore, off-pump BLT has become the technique of choice at many institutions.

Lung transplant recipients are assumed to be at high risk of perioperative hypothermia because of exposure of a large body surface area, the complicated and prolonged nature of the operation, and the implantation of an ice-cooled graft. Moreover, avoiding hypothermia during off-pump lung transplantation can be particularly challenging, given that it is not possible to warm circulating blood through a heat exchanger equipped to a CPB or ECMO circuit. To our knowledge, changes in body temperature (BT) during lung transplantation have never been reported.

We investigated the time-dependent changes in BT during cadaveric lung transplantation, during which a multimodal approach was used to prevent hypothermia. The primary aim of this study was to compare BT decrease during the operation in 
patients treated by off-pump lung transplantation with that in patients treated by ECMO-supported lung transplantation.

\section{Methods}

After obtaining the approval of the Institutional Review Board (the approval number: E2511), we retrospectively analyzed the medical records of patients undergoing cadaveric lung transplantation at Kyoto University Hospital between January 2008 and January 2015. We excluded patients who received cardiopulmonary support by CPB because induced hypothermia was used during CPB in these patients. The requirement for written informed consent was waived because of retrospective design.

\section{Data collection}

Specific data were collected from medical records, including the characteristics of both patients and operations, the intraoperative BT at different time points, and the occurrence of intra- and postoperative arrhythmias. BT was measured by a bladder catheter equipped with a temperature probe, and was automatically recorded every minute by an anesthesia information management system (Nihon Kohden, Tokyo, Japan). BT measured using a thermistor equipped in the pulmonary artery catheter (CCOmbo Continuous Cardiac Output Catheter with $\mathrm{SvO}_{2}$ and EDV, Edwards Lifesciences, CA, USA) was also recorded. We collected temperature data at the following predetermined time points: $1 \mathrm{~h}$ after anesthetic induction, at the time of graft placement and reperfusion, 30 and 60 min after final reperfusion, and at the time of exit from the operating room. Because the bladder catheter was inserted after anesthetic induction, bladder temperature immediately after anesthetic induction was not recorded. 
Time from anesthetic induction to bladder catheter insertion was $20 \mathrm{~min}$ at median, and it was several minutes before the bladder temperature stabilized. Therefore, we decided to use BT $1 \mathrm{~h}$ after anesthetic induction as the baseline. The lowest BT during the operation was also recorded, and the decrease in BT during the operation was calculated with the following equation: $\mathrm{BT}$ decrease $=(\mathrm{BT} 1 \mathrm{~h}$ after anesthetic induction $)-($ the lowest BT during the operation). Arrhythmia was defined as any cardiac arrhythmia requiring treatment by cardioversion or with an antiarrhythmic agent, including atrial flutter, paroxysmal atrial fibrillation, paroxysmal supraventricular tachycardia, ventricular tachycardia, and ventricular fibrillation.

\section{Anesthetic management and strategies to prevent intraoperative hypothermia}

Patients received no premedication. After preoxygenation for at least $3 \mathrm{~min}$, rapid induction with propofol or midazolam plus opioids was completed in all but one patient, who had difficulty opening his mouth; in this case, we used semiconscious fiber-optic intubation. Rocuronium was used to facilitate endotracheal intubation following bag and mask ventilation. Anesthesia was maintained with $1 \%-2 \%$ sevoflurane combined with infusions of remifentanil and rocuronium. In our center, we do not use epidural catheters during lung transplantation surgeries.

We routinely used several strategies to prevent intraoperative hypothermia, as follows. 1) The ambient operating room temperature was set at $26^{\circ} \mathrm{C}$ during the anesthetic induction, and gradually decreased to $24^{\circ} \mathrm{C}$ thereafter. 2) Patients were pre-warmed with a convective forced-air warmer (3M $\mathrm{M}^{\mathrm{TM}}$ Bair Hugger ${ }^{\mathrm{TM}}$ Model 750 Warming Unit, 3M Health Care, MN, USA) during the anesthetic induction. After anesthetic induction, forced-air warming was applied only to the legs below the knee, and the patient's body 
above the knee was fully exposed to the ambient environment. 3) Spillage of cold fluids on the patient was avoided by draping the patient with waterproof sheets. 4) Intravenously administered fluids and blood products were warmed by fluid warmers (Level 1® HOTLINE® Blood and Fluid Warmer, Smiths Medical, MN, USA). 5) A circulating water warming pad (MUL-T-PAD Temperature Therapy Pad TP26E, Stryker Medical, MI, USA) was laid under the body and water warmed to $38^{\circ} \mathrm{C}$ using a heater-cooler system (Mera, HHC-211D, Senko Medical Instrument Manufacturing co., Ltd., Tokyo, Japan) was circulated.

Indications for ECMO were not fixed and depended on patient need. Common reasons for using ECMO were persistent hypoxia or severe respiratory acidosis during one lung ventilation and acute pulmonary hypertension after clamping pulmonary artery. When ECMO (HAS-CFP, Senko Medical Instrument Manufacturing co., Ltd., Tokyo, Japan) was used, the water in the heater-cooler system (HHC-51, Senko Medical Instrument Manufacturing co., Ltd., Tokyo, Japan) was warmed to $37^{\circ} \mathrm{C}$ and connected to the heat exchanger of the ECMO circuit.

\section{Statistical analyses}

Data were analyzed using the statistical program R (http://cran.r-project.org).

Continuous data are presented as median (inter-quartile range) and categoric variables are expressed as a number (percentage), unless stated otherwise. Differences between groups were compared using the Mann-Whitney $U$ test for continuous variables, and the Pearson chi-square or Fisher exact tests, as appropriate, for categorical variables. All the statistical tests were two-tailed and the statistical significance was set at $\mathrm{P}<0.05$. To compare the BT decrease during the operation among patients undergoing off-pump 
BLT, ECMO-supported BLT, off-pump SLT, and ECMO-supported SLT, statistical significance was set at 0.083 using Bonferroni corrections $(\mathrm{P}<0.05 / 6)$.

\section{Results}

The study flow diagram is presented in Figure 1. Forty-nine patients underwent cadaveric lung transplantation during the study period. After excluding three patients who received CPB and induced hypothermia, 46 patients were studied. The ages of the patients ranged from 20 to 61 years, and 16 patients $(34.8 \%)$ were female. Of the 15 patients who underwent BLT, $10(66.7 \%)$ required ECMO support during the operation. Among the 31 patients who underwent SLT, 11 (35.5\%) required ECMO support. There were no significant differences in patient or operative variables between those who received ECMO support and those who did not among patients undergoing BLT. Patient characteristics were also comparable between off-pump SLT and ECMO-supported SLT, but patients undergoing ECMO-supported SLT had more blood loss than those undergoing off-pump SLT (Table 1).

The time course of BT during BLT is presented in Figure 2A. In patients undergoing off-pump BLT, BT continuously decreased until final reperfusion, when the mean BT was as low as $32.9^{\circ} \mathrm{C}$. Thereafter, BT gradually recovered, and the mean BT was $34.6^{\circ} \mathrm{C}$ at the time of exit from the operating room among patients undergoing off-pump BLT. In contrast, BT was stable during ECMO-supported BLT, and only two patients $(20.0 \%)$ experienced significant hypothermia $\left(\mathrm{BT}<35.5^{\circ} \mathrm{C}\right)$. At all time points except for $1 \mathrm{~h}$ after anesthetic induction, BTs were significantly lower in patients undergoing offpump BLT when compared with patients undergoing ECMO-supported BLT. Compared with patients undergoing off-pump BLT, patients undergoing off-pump SLT 
had a similar time trend for their BTs (continuous decrease until reperfusion and subsequent recovery). However, the extent of the BT decrease was much smaller $\left(35.6^{\circ} \mathrm{C}\right.$ at the time of reperfusion and $36.0^{\circ} \mathrm{C}$ at the time of exit from the operating room, Fig 2B). No patients undergoing ECMO-supported SLT experienced significant hypothermia $\left(\mathrm{BT}<35.5^{\circ} \mathrm{C}\right)$.

The BT decrease during the operation was compared among patients undergoing offpump BLT, ECMO-supported BLT, off-pump SLT, and ECMO-supported SLT (Fig 3). In patients undergoing off-pump BLT, the BT decrease was significantly larger than that in patients undergoing ECMO-supported BLT $\left(3.5^{\circ} \mathrm{C} \pm 0.5^{\circ} \mathrm{C}\right.$ compared with $0.6^{\circ} \mathrm{C}$ $\pm 0.5^{\circ} \mathrm{C}, \mathrm{P}=0.002$ ), and was $3^{\circ} \mathrm{C}$ or more in all patients. Similarly, BT decrease in patients undergoing off-pump SLT was significantly larger than that in patients undergoing ECMO-supported SLT $\left(1.0^{\circ} \mathrm{C} \pm 0.7^{\circ} \mathrm{C}\right.$ vs. $\left.0.3^{\circ} \mathrm{C} \pm 0.3^{\circ} \mathrm{C}, \mathrm{P}=0.001\right)$. Although the BT decrease in patients undergoing off-pump SLT was significantly smaller than that in patients undergoing off-pump BLT, 9 of the 19 patients undergoing off-pump SLT (47.4\%) experienced a significant decrease in $\mathrm{BT}$ of $1^{\circ} \mathrm{C}$ or more during the operation, with a maximum BT decrease of $2.8^{\circ} \mathrm{C}$ among patients undergoing offpump SLT.

The time course of BT and BT decrease during the operation were also analyzed using BT measured using a thermistor equipped in the pulmonary artery catheter, and similar results to the analysis of bladder temperature were obtained; BT continuously decreased until final reperfusion in patients undergoing off-pump lung transplantation, and BT decrease in patients undergoing off-pump lung transplantation was significantly larger than ECMO-supported lung transplantation (Supplemental Figures 1 and 2).

The incidences of intra- and postoperative arrhythmia stratified by the type of operation 
and ECMO use are presented in Table 2. The incidence of intraoperative arrhythmia was $80.0 \%$ in the patients undergoing off-pump BLT and $40.0 \%$ in the patients undergoing ECMO-supported BLT. On the other hand, no intraoperative arrhythmias were observed in patients undergoing SLT.

Four patients undergoing off-pump BLT experienced intra- or postoperative arrhythmias, and their details are summarized in Table 3. Among the four patients who experienced intraoperative arrhythmia, three experienced paroxysmal atrial fibrillation and one experienced a paroxysmal supraventricular tachycardia. All arrhythmic episodes occurred during implantation procedures (from first graft placement until final reperfusion), and BT at the onset of arrhythmia ranged from $32.8^{\circ} \mathrm{C}$ to $34.0^{\circ} \mathrm{C}$. All four patients who experienced intraoperative arrhythmias received electrical cardioversion and three received additional antiarrhythmic agents.

After the lung transplantation surgery, patients were transferred to our intensive care unit and warmed using a forced-air warming blanket that covered the whole body. In all patients, BT recovered to $36.0^{\circ} \mathrm{C}$ or more within $6 \mathrm{~h}$ after admission to intensive care.

\section{Discussion}

We investigated the changes in BT during cadaveric lung transplantation. The retrospective data indicated that patients undergoing off-pump BLT experienced a profound decrease in BT, which continuously decreased until final reperfusion and gradually recovered thereafter. Decrease in BT during off-pump BLT was significantly greater than that during ECMO-supported BLT, and was $3{ }^{\circ} \mathrm{C}$ or more in all cases. To the best of our knowledge, this is the first study to report profound hypothermia as a complication accompanying off-pump lung transplantation. 
Previous studies of intraoperative core temperature patterns in patients warmed with forced-air have shown that core temperatures decrease during the first hour of surgery, because of core-to-peripheral redistribution, before progressively increasing [8]. However, although we also used a forced-air warmer during the operation, the time course of BT change differed in our patients undergoing off-pump BLT; after the initial hour of anesthesia, BT continued to decrease until final reperfusion, and gradually increased thereafter. This unique time course implies that hypothermia during lung transplantation is caused by a mechanism other than core-to-peripheral redistribution.

There are many reasons for the continuing decrease of BT after core-to-peripheral redistribution, including the following. First, in order to prepare for urgent initiation of ECMO in the event of severe cardiorespiratory instability, a large body surface area was exposed during the operation (from chest to femur). Second, the forced-air warming device was only applied to a small area of the body (below the knee). Third, to improve tissue preservation, donor lungs were treated by flushing of the pulmonary vascular bed with cold preservation solution and kept in a cold ice box, and the chest cavity of the recipient was also covered with ice slush during implantation; these aggressive cooling procedures, in particular, might have caused profound BT decreases before final reperfusion.

The BT decrease in patients undergoing ECMO-supported BLT was much smaller than that in patients undergoing off-pump BLT, and the same was true for patients undergoing ECMO-supported SLT compared with those undergoing off-pump SLT. Patients receiving ECMO support were probably at lower risk of profound hypothermia because of the active warming of circulating blood through the heat exchanger equipped to the ECMO circuit. Although the extent of BT decrease was smaller than that in 
patients undergoing off-pump BLT, many patients undergoing off-pump SLT also experienced significant BT decrease, to a maximum $2.8^{\circ} \mathrm{C}$. Therefore, patients undergoing either single or bilateral off-pump lung transplantation should be considered high risk for profound intraoperative hypothermia.

Atrial tachyarrhythmias, most commonly atrial fibrillation, are highly prevalent postoperative complications of lung transplantation with reported incidences of $20 \%-$ 45\% [9-12]. However, to our knowledge, no previous study has reported either the incidence or the timing when intraoperative arrhythmias occurred in this setting. The incidence of intraoperative arrhythmia in patients undergoing off-pump BLT was as high as $80.0 \%$ in our study. There are several possible explanations for this extremely high incidence of intraoperative arrhythmias in patients undergoing off-pump BLT. The fact that all arrhythmic episodes occurred during the implantation procedures (from the time of first graft placement to final reperfusion) suggests that direct mechanical stimulation by heart retraction might have triggered an arrhythmia. In addition, BT at the onset of arrhythmia was $34^{\circ} \mathrm{C}$ or lower in all patients. Although causation between hypothermia and arrhythmias cannot be proven using the data presented in this study, elevated catecholamine levels due to profound hypothermia [13] might have contributed to increased susceptibility to an arrhythmia.

Although we used a multimodal approach to prevent the development of intraoperative hypothermia, additional interventions may be needed to improve BT maintenance during lung transplantation. For example, the use of an underbody forced-air or resistive mattress [14-16] might be effective in lung transplantation. This is because lung transplantation relies on a forced-air warming blanket that can only be applied to a small area because of the need for exposure of a large body surface area. 
Arguably, there may be some advantages to transient hypothermia. For example, some studies have reported neuroprotective effects associated with hypothermia during brain ischemia $[17,18]$. Intraoperative mild hypothermia might also be beneficial in lung transplantation recipients, who often experience hemodynamically unstable periods during which the brain suffers hypo-perfusion. However, data are limited regarding the neuroprotective effect of intraoperative hypothermia and optimal BT during the surgery with high risk of brain ischemia. Further work is needed to address the risks and benefits of intraoperative hypothermia in lung transplantation settings.

This study suffered certain limitations based primarily on its retrospective, single-center design. The sample size was also too small to estimate the incidence of intraoperative arrhythmia precisely. Bladder temperature was not an ideal way to monitor core temperature; however, similar results were obtained from BT measured using a thermistor equipped in the pulmonary artery catheter, which strengthened the bladder temperature results. Despite these limitations, our data provide valuable information regarding the intraoperative management of BT in lung transplant recipients.

In conclusion, patients undergoing off-pump BLT were at high risk of profound intraoperative hypothermia despite using a multimodal preventive approach. In addition, profound hypothermia might have contributed to the high incidence of intraoperative atrial arrhythmia. 


\section{References}

1. Frank SM, Fleisher LA, Breslow MJ, et al: Perioperative maintenance of normothermia reduces the incidence of morbid cardiac events. A randomized clinical trial. JAMA 277:1127-34, 1997

2. Kurz A, Sessler DI, Lenhardt R: Perioperative normothermia to reduce the incidence of surgical-wound infection and shorten hospitalization. Study of Wound Infection and Temperature Group. N Engl J Med 334:1209-15, 1996

3. Schmied H, Kurz A, Sessler DI, et al: Mild hypothermia increases blood loss and transfusion requirements during total hip arthroplasty. Lancet 347:289-92, 1996

4. Lenhardt R, Marker E, Goll V, et al: Mild intraoperative hypothermia prolongs postanesthetic recovery. Anesthesiology 87:1318-23, 1997

5. Corris PA, Christie JD: Update in transplantation 2007. Am J Respir Crit Care Med $177: 1062-7,2008$

6. Yusen RD, Edwards LB, Kucheryavaya AY, et al: The Registry of the International Society for Heart and Lung Transplantation: Thirty-second Official Adult Lung and Heart-Lung Transplantation Report-2015; Focus Theme: Early Graft Failure. J Heart Lung Transplant 34:1264-77, 2015

7. Kaiser LR, Pasque MK, Trulock EP, Low DE, Dresler CM, Cooper JD: Bilateral sequential lung transplantation: the procedure of choice for double-lung replacement. Ann Thorac Surg 52:438-45, 1991

8. Sun Z, Honar H, Sessler DI, et al: Intraoperative core temperature patterns, transfusion requirement, and hospital duration in patients warmed with forced air. Anesthesiology 122:276-85, 2015 
9. Nielsen TD, Bahnson T, Davis RD, et al: Atrial fibrillation after pulmonary transplant. Chest 126:496-500, 2004

10. Mason DP, Marsh DH, Alster JM, et al: Atrial fibrillation after lung transplantation: timing, risk factors, and treatment. Ann Thorac Surg 84:1878-1884, 2007

11. Isiadinso I, Meshkov AB, Gaughan J, et al: Atrial arrhythmias after lung and heartlung transplant: effects on short-term mortality and the influence of amiodarone. J Heart Lung Transplant 30:37-44, 2011

12. Orrego CM, Cordero-Reyes AM, Estep JD, et al: Atrial arrhythmias after lung transplant: underlying mechanisms, risk factors, and prognosis. J Heart Lung Transplant $33: 734-740,2014$

13. Frank SM, Higgins MS, Breslow MJ, et al: The catecholamine, cortisol, and hemodynamic responses to mild perioperative hypothermia. A randomized clinical trial. Anesthesiology 82:83-93, 1995

14. Insler SR, Bakri MH, Nageeb F, Mascha E, Mihaljevic T, Sessler DI: An evaluation of a full-access underbody forced-air warming system during near-normothermic, onpump cardiac surgery. Anesth Analg 106:746-50, 2008

15. Engelen S, Himpe D, Borms S, et al: An evaluation of underbody forced-air and resistive heating during hypothermic, on-pump cardiac surgery. Anaesthesia 66:104-10, 2011

16. Egan C, Bernstein E, Reddy D, et al: A randomized comparison of intraoperative PerfecTemp and forced-air warming during open abdominal surgery. Anesth Analg $113: 1076-81,2011$

17. Busto R, Dietrich WD, Globus MY, et al: The importance of brain temperature in cerebral ischemic injury. Stroke 20:1113-4, 1989 
18. Busto R, Dietrich WD, Globus MY, et al: Small differences in intraischemic brain temperature critically determine the extent of ischemic neuronal injury. J Cereb Blood Flow Metab 7:729-38, 1987 
Figure captions

Fig 1. Flow diagram of study population.

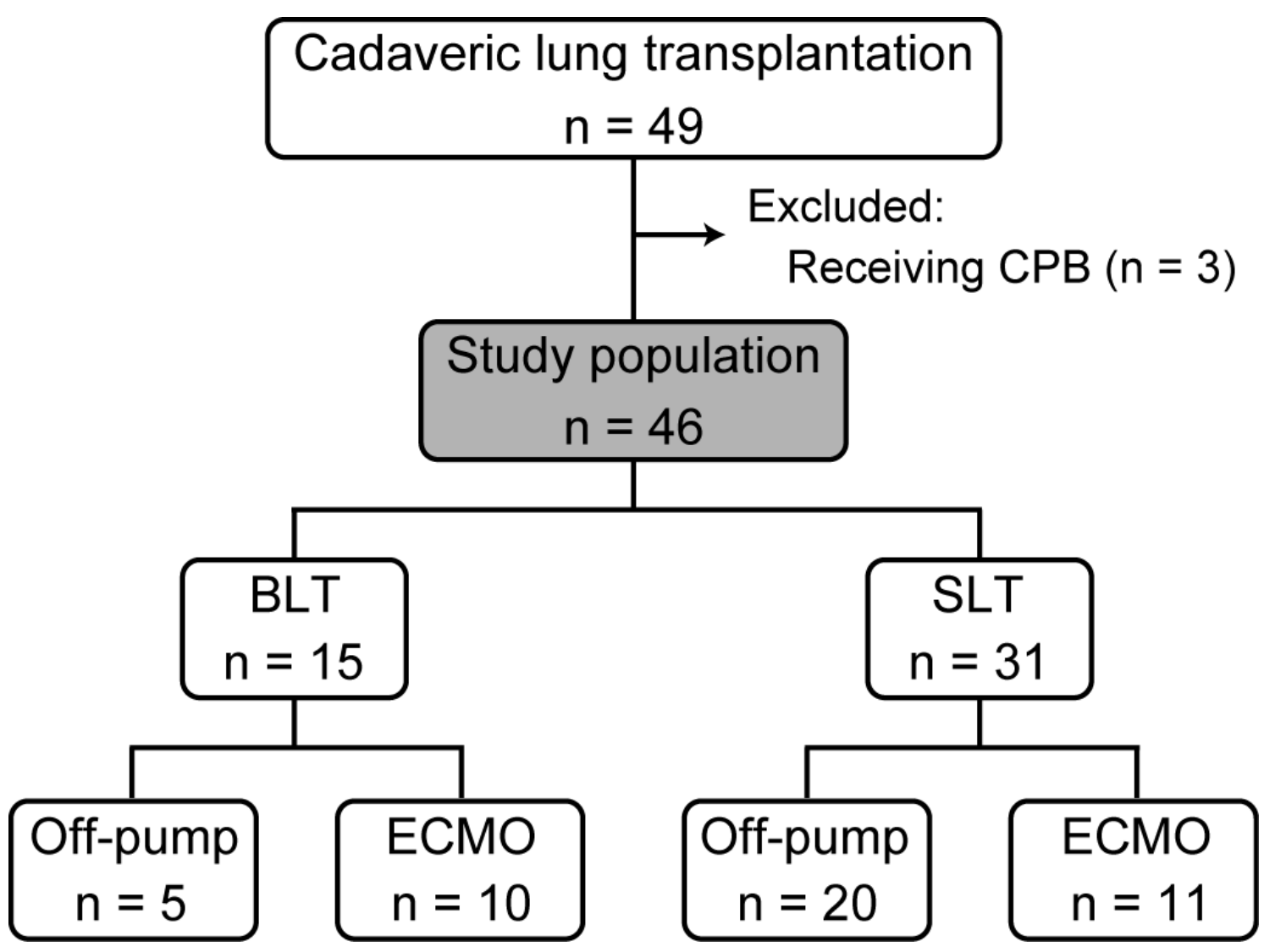

Fig 2. Time course of bladder temperature during (A) bilateral and (B) single lung transplantation. Data are given as mean and standard deviation. ${ }^{*} \mathrm{P}<0.05 ; * * \mathrm{P}<0.01$. T1, $1 \mathrm{~h}$ after anesthetic induction; T2 (and T2'), graft placement; T3 (and T3'), reperfusion; T4, 30 min after final reperfusion; T5, 60 min after final reperfusion; T6, exit from the operating room. 

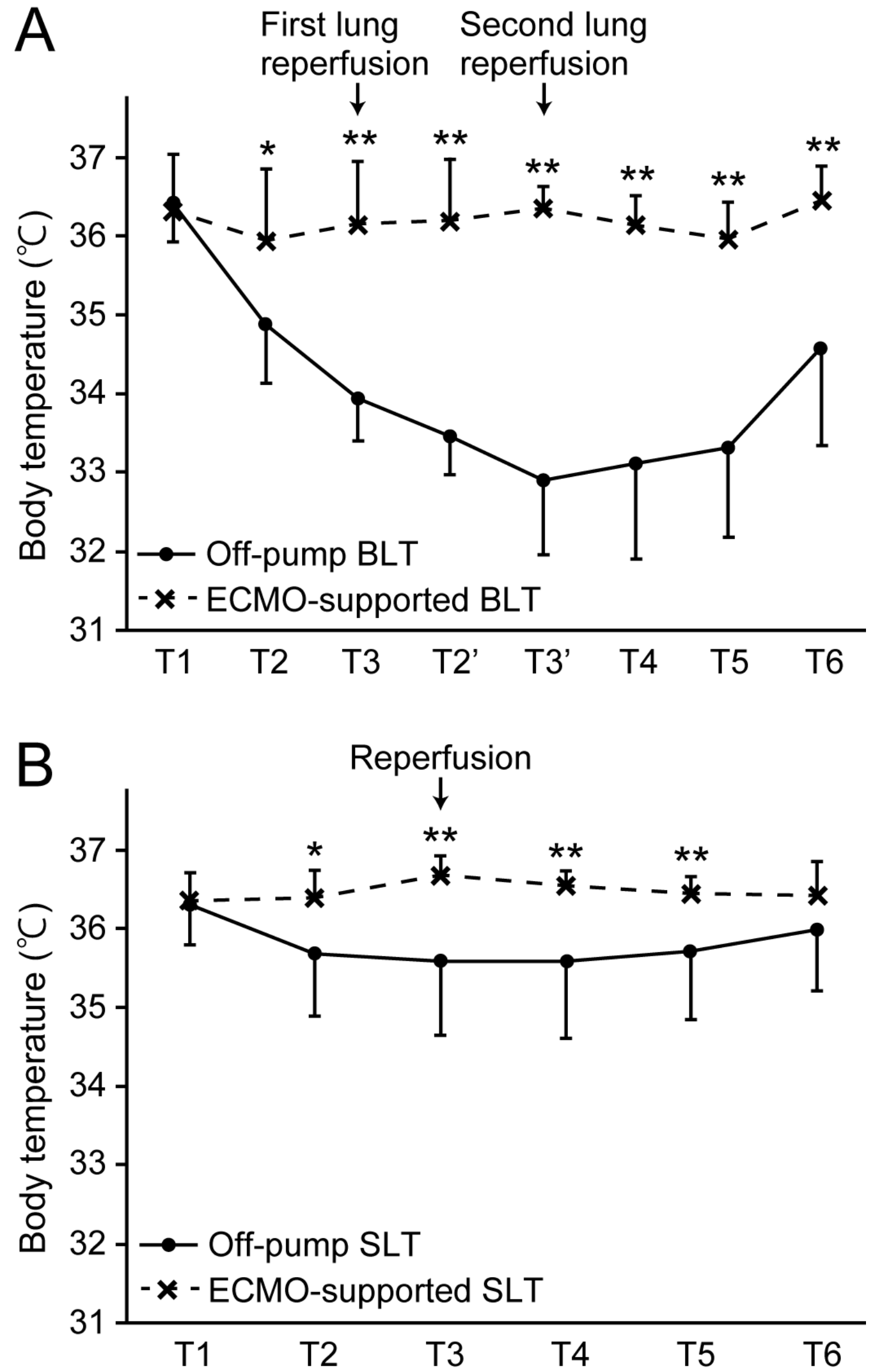
Fig 3. Decrease in bladder temperature during the operation stratified by type of operation and ECMO use. $\triangle \mathrm{BT}$, decrease in body temperature during the operation; BLT, bilateral cadaveric lung transplantation; SLT, single cadaveric lung transplantation; ECMO, extracorporeal membrane oxygenation.

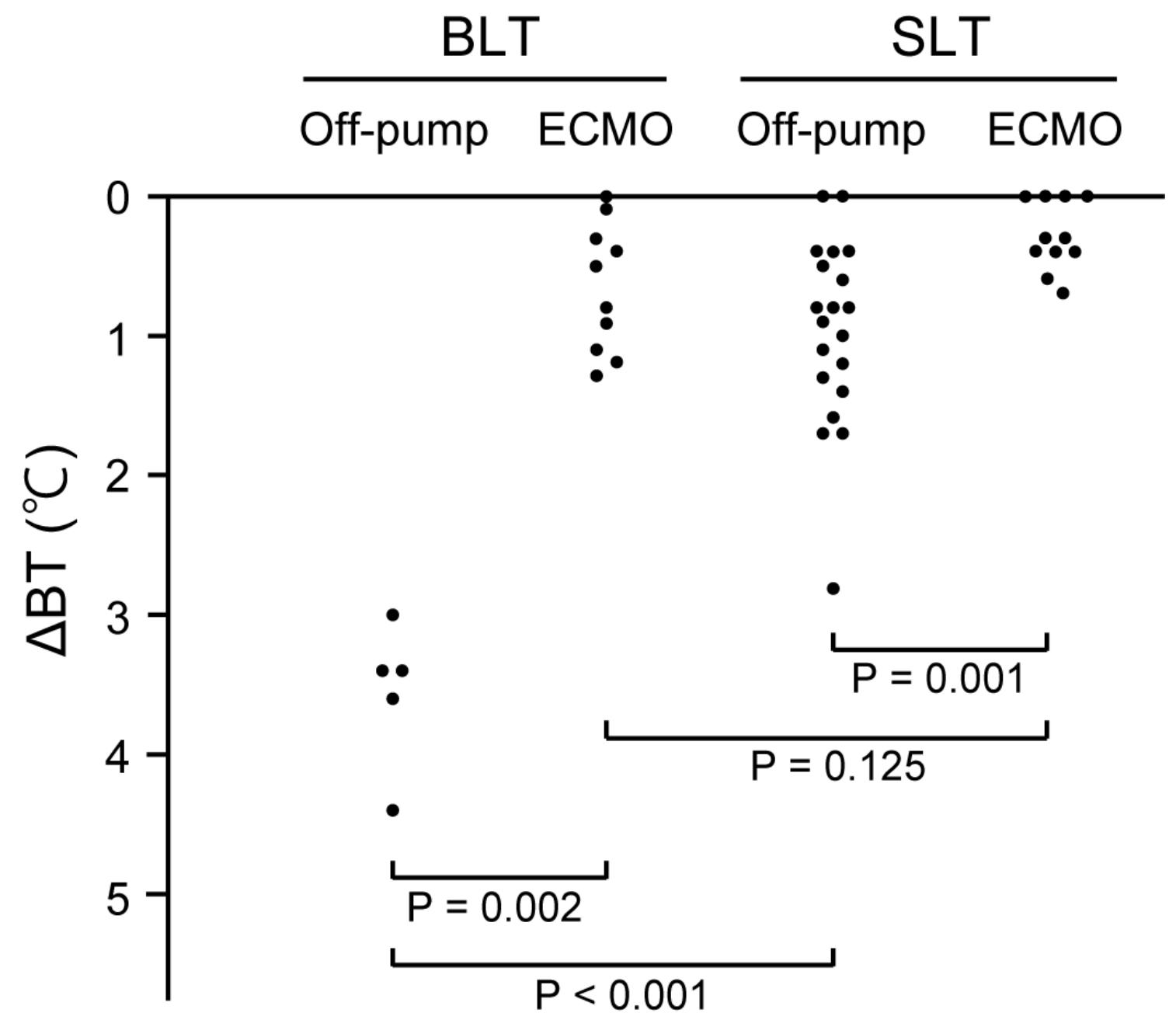




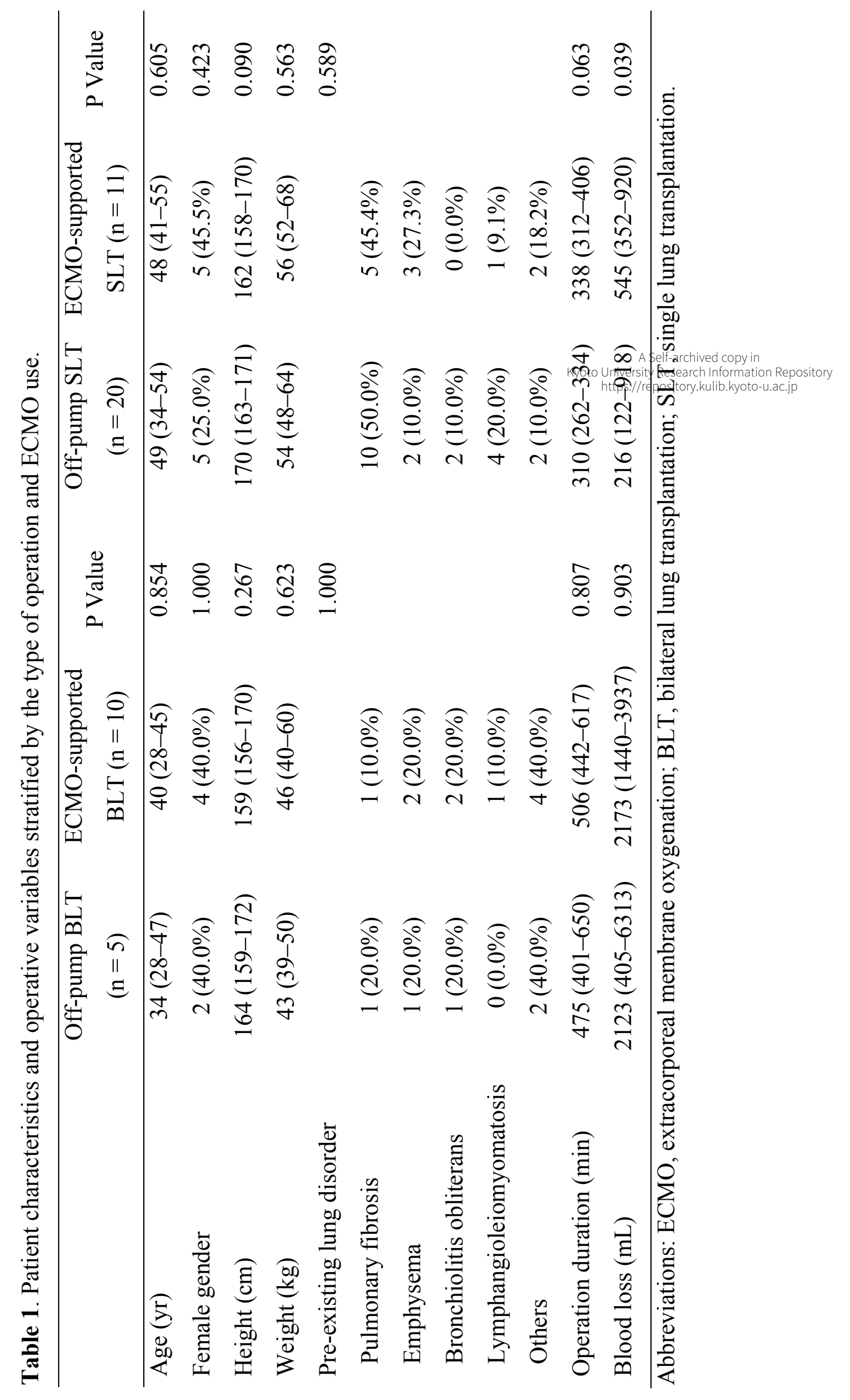




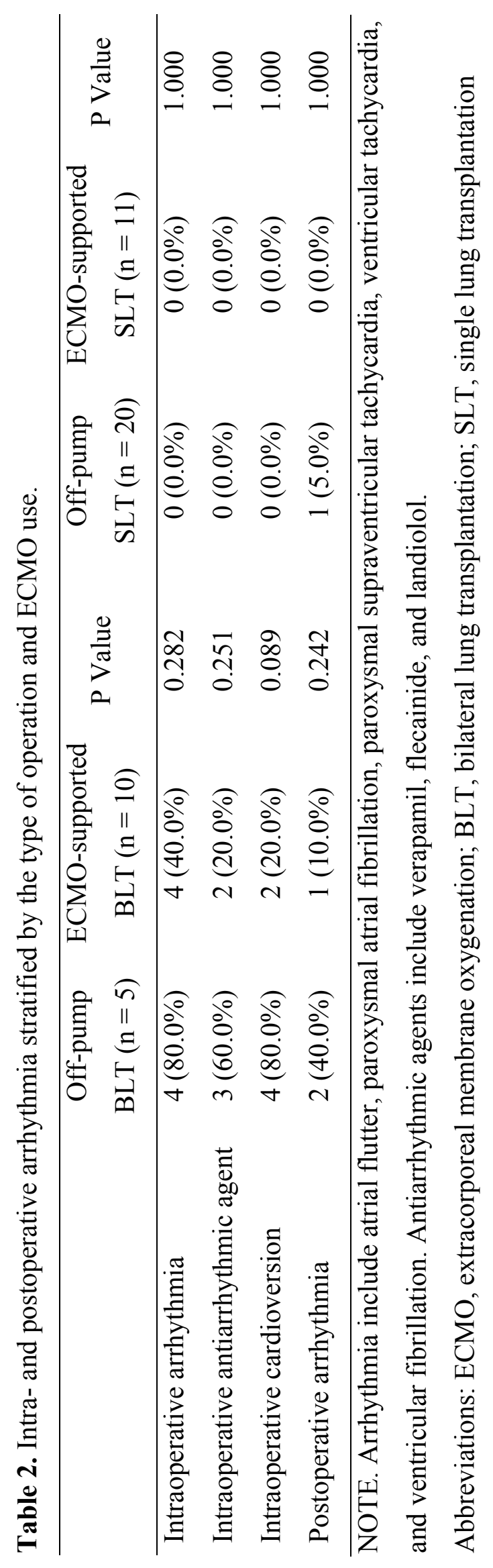




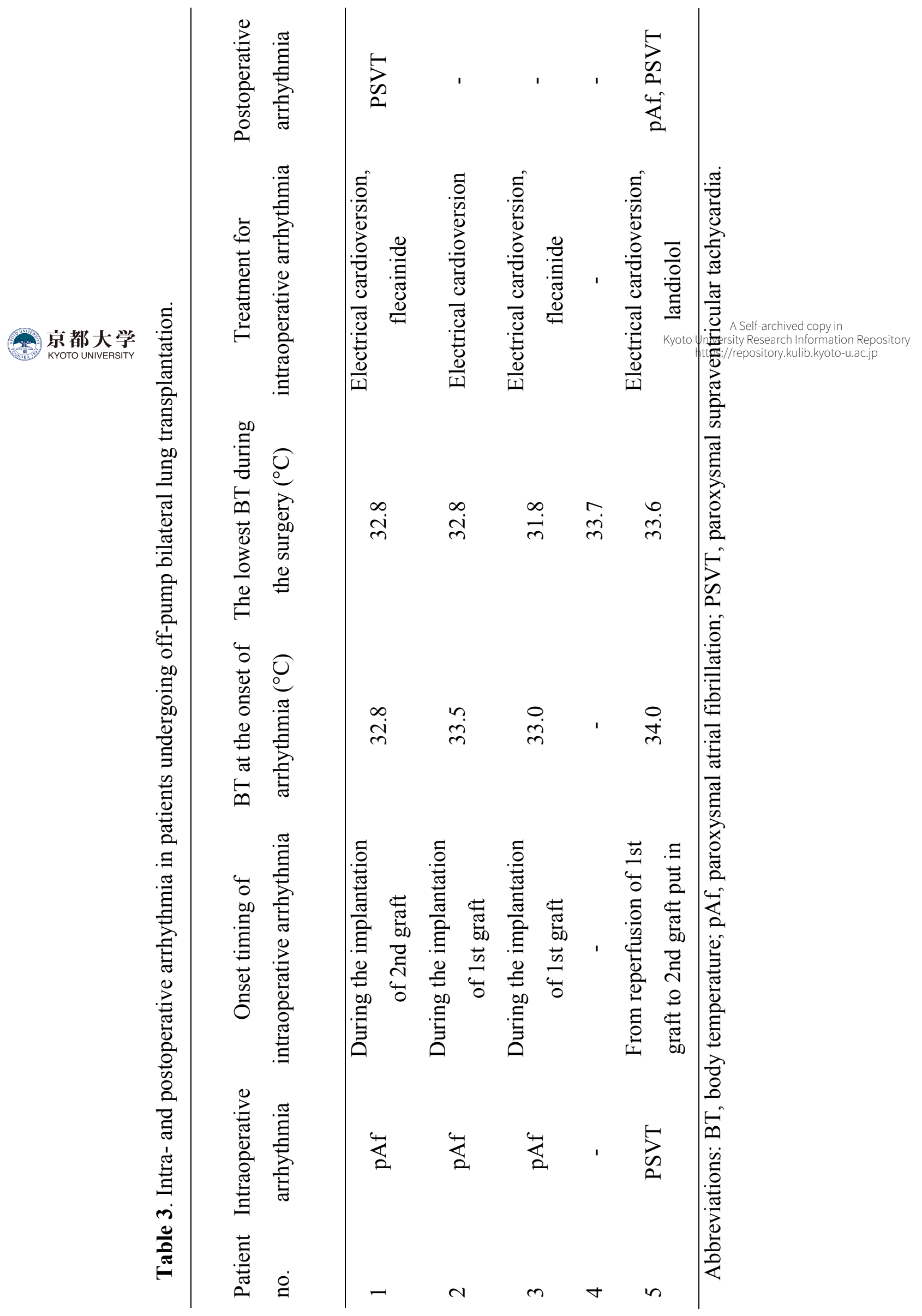




\section{Figure captions for Supplemental Figures}

Supplemental Fig 1. Time course of BT (measured using a thermistor equipped in the pulmonary artery catheter) during (A) bilateral and (B) single lung transplantation. Data on BT were missed in one off-pump BLT patient, three ECMO-supported BLT patients, four off-pump SLT patients, and one ECMO-supported SLT patient. Data are given as mean and standard deviation. ${ }^{*} \mathrm{P}<0.05,{ }^{*} \mathrm{P}<0.01$. BT, body temperature; BLT, bilateral cadaveric lung transplantation; SLT, single cadaveric lung transplantation; ECMO, extracorporeal membrane oxygenation; T1, $1 \mathrm{~h}$ after anesthetic induction; T2 (and T2'), graft placement; T3 (and T3'), reperfusion; T4, $30 \mathrm{~min}$ after final reperfusion; T5, 60 min after final reperfusion; T6, exit from the operating room. 
A First lung Second lung

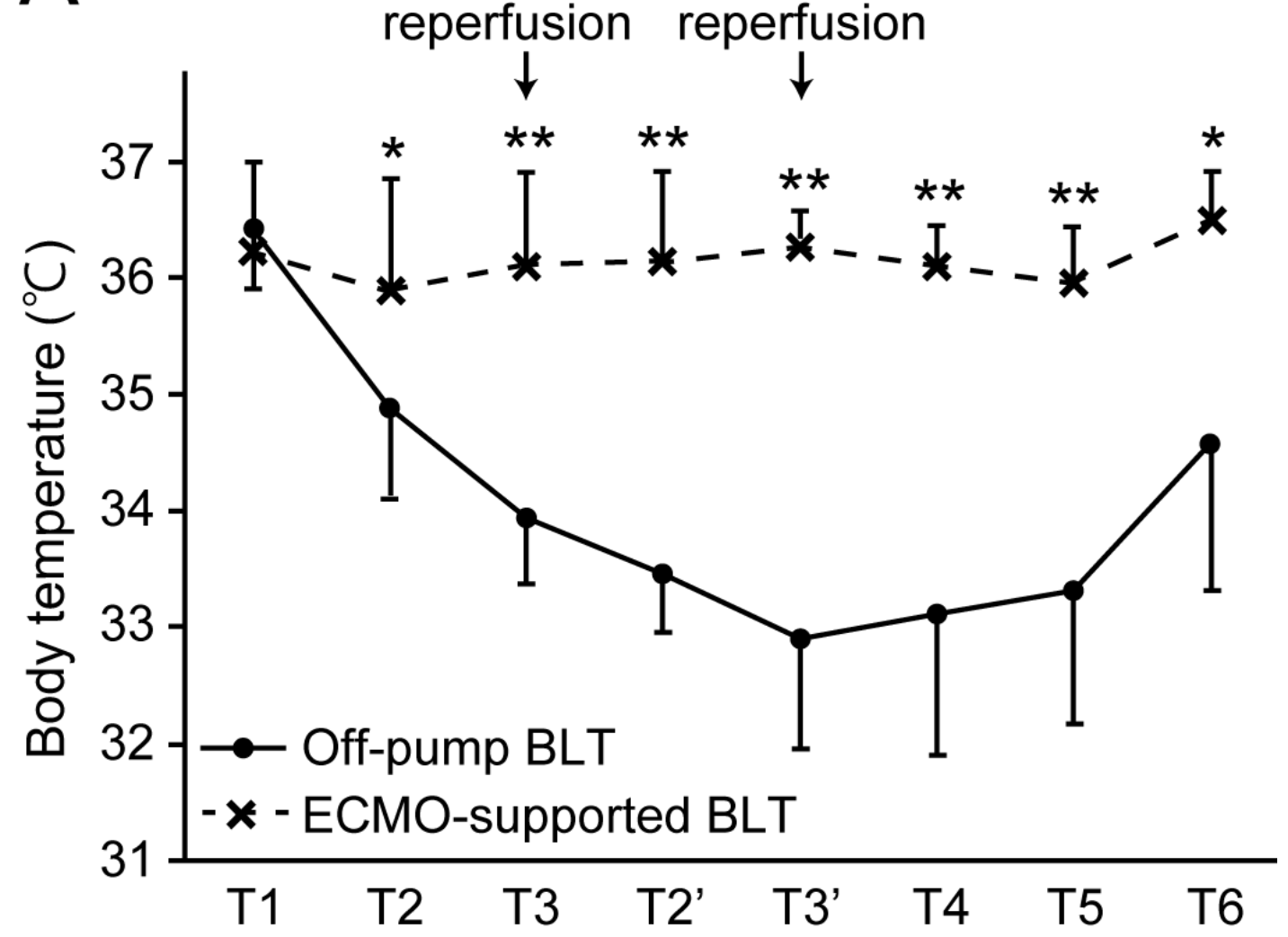

B

Reperfusion

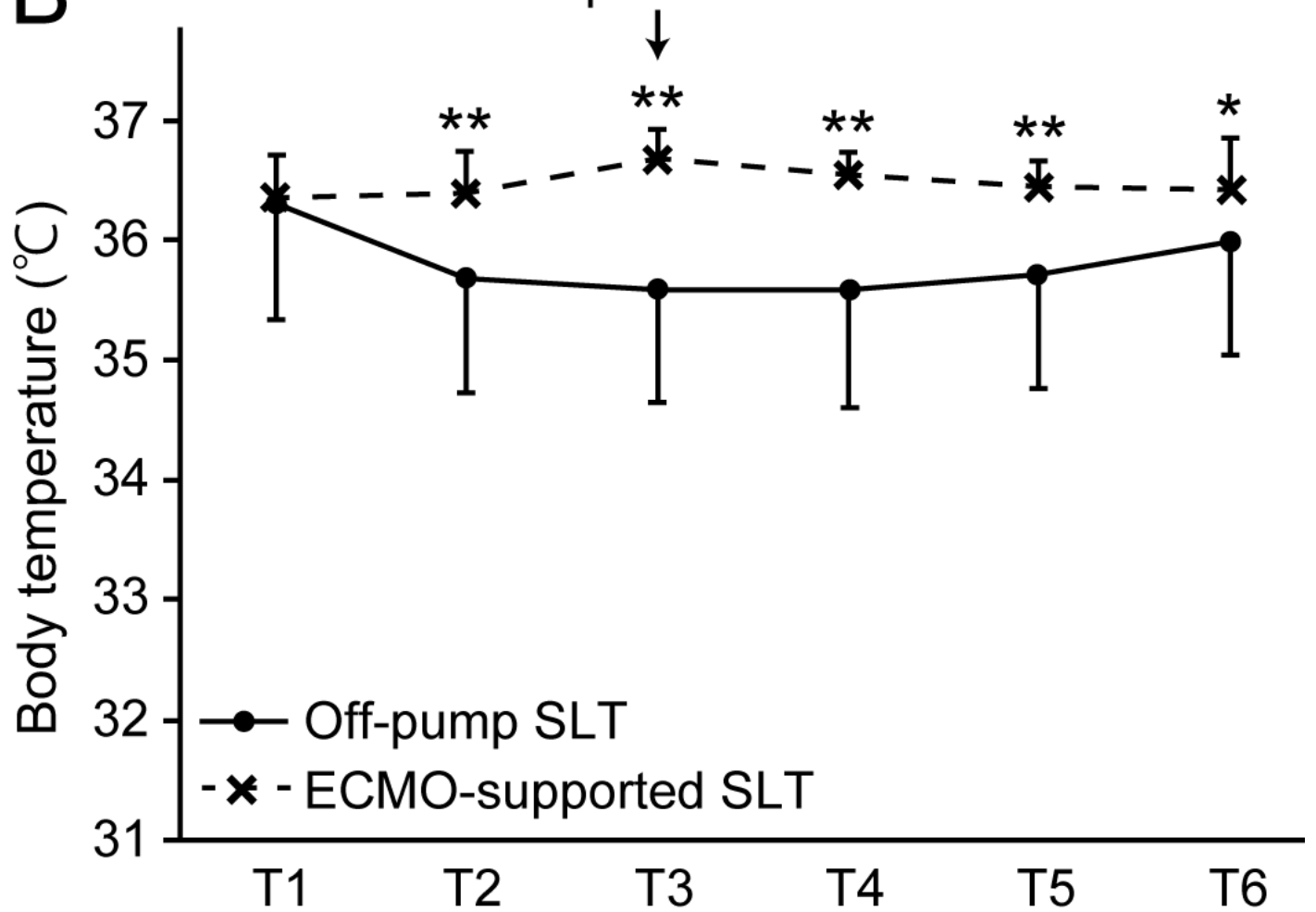


Supplemental Fig 2. Decrease in BT (measured using a thermistor equipped in the pulmonary artery catheter) during the operation stratified by type of operation and ECMO use. Data on BT were missed in one off-pump BLT patient, three ECMOsupported BLT patients, four off-pump SLT patients, and one ECMO-supported SLT patient. $\mathrm{BT}$, body temperature; $\triangle \mathrm{BT}$, decrease in body temperature during the operation; BLT, bilateral cadaveric lung transplantation; SLT, single cadaveric lung transplantation; ECMO, extracorporeal membrane oxygenation.

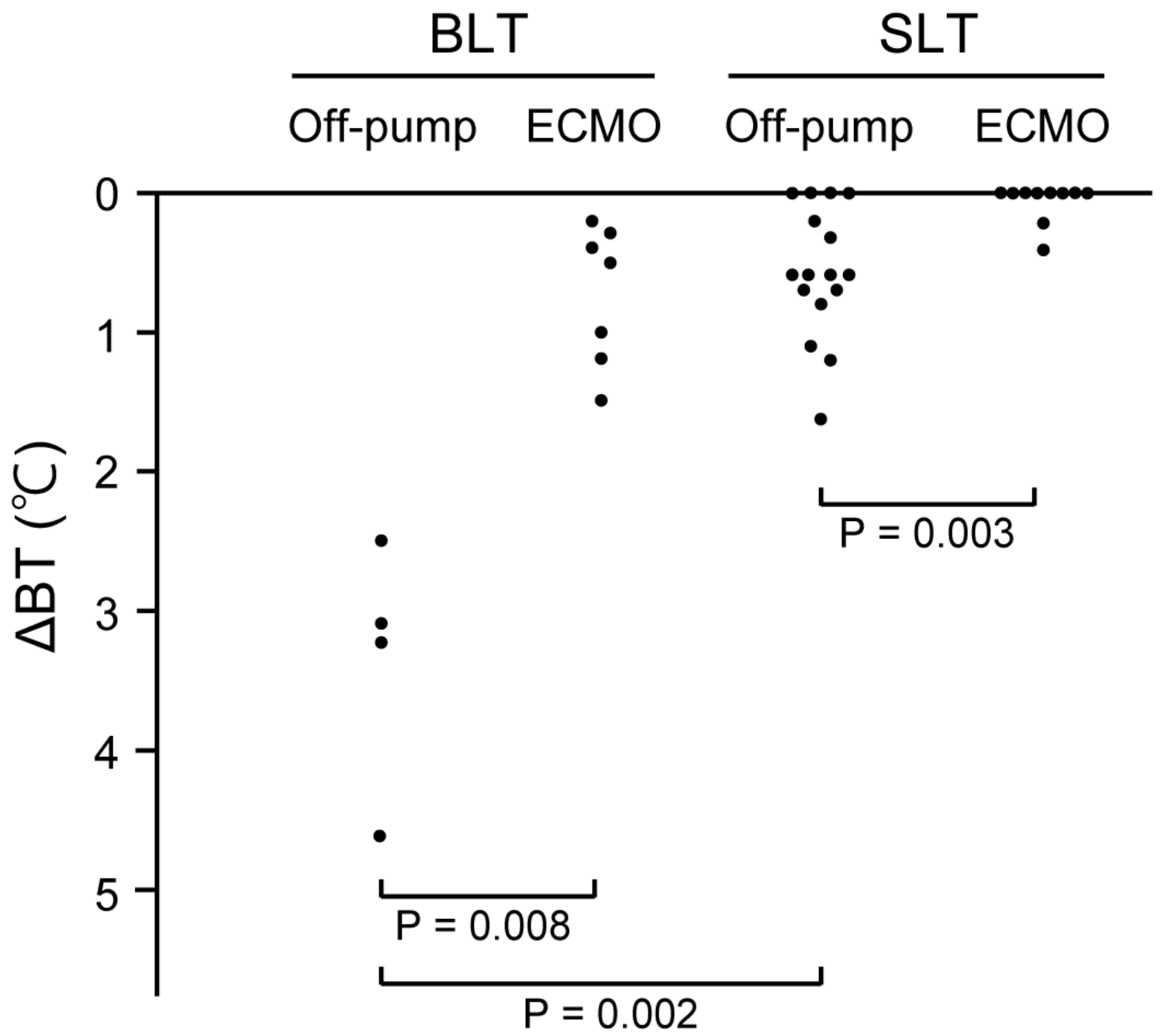

